\title{
Reversing perverted development: magical realism in Moses, Citizen \& Me
}

Cecilia Addei

\section{Reversing perverted development: magical realism in Moses, Citizen \& Me}

This paper focuses on reimagining the developmental process of the child soldier who has developed abnormally into adulthood and bringing him back into normal childhood. In particular, it considers how the attention of Delia Jarrett-Macauley's novel, Moses, Citizen \& Me (2005) is directed at restoring the childhood of the child soldier. The novel achieves this aim through employing creative narrative techniques to take the monstrous adult that the child has become, through a reverse-development, back to childhood from which the child may be re-educated and re-formed. The novel thus represents how the child soldier whose experience has turned him into some kind of 'monster' may be restored to humanity. The paper argues that magical realism in Moses, Citizen \& Me encompasses a therapeutic tendency that represents a form of healing for child soldiers. Keywords: child soldiers, reverse development, magical realism, Moses, Citizen \& Me.

\section{Introduction}

Delia Jarrett-Macauley, a Briton born to Sierra Leonean parents, was drawn to write about child soldiers through her work experience in war-torn Central and Eastern Europe, and through a documentary about the civil war in Sierra Leone. Moses, Citizen $\mho$ Me begins when Julia, a British citizen with Sierra Leonean parents, arrives in Sierra Leone after the end of the civil war that lasted for about ten years. Julia had been called by Anita, the neighbour of her maternal uncle Moses, to come to Sierra Leone to comfort her bereaved uncle. Moses' beloved wife, Adele, was killed during the war. Julia finds Citizen, the eight-year-old orphaned son of her cousin, rejected and dejected. Citizen is a former child soldier who refuses to speak. She discovers, as Moses had, that Citizen, under instruction from "the big soldier man" (2), had killed his own grandmother, Adele. Anita encourages Julia to help both her uncle Moses and her cousin's son, Citizen.

In spite of the fact that most people feel that child soldiers cannot be redeemed, Julia feels obliged to restore Citizen to normal childhood. Julia's commitment to restoring Citizen to normalcy leads her to visit Doria camp, a rehabilitation camp for former child soldiers where Citizen was found by Elizabeth, Anita's daughter, who brought him home. At Doria camp, Julia meets Sally, a girl soldier who tells her how she and Citizen had escaped from the war front to the rehabilitation centre. At the rehabilitation centre, Julia finds several other former child soldiers, some mutilated and some drug addicts, undergoing rehabilitation under an Irish priest.

Inspired by this visit, Julia imagines bringing the child soldiers back to normal development and normal relations with their families. She resolves to return to the camp and is not in the least surprised when she returns instead through a magical experience that superimposes the female socialisation activity of hair braiding onto the restorative return. One day, as Anita, the neighbour, plaits her hair, Julia observes strange scenes she has not observed before. She is taken into the dream world of Gola forest where she meets the child soldiers of the "number-one-burn-house unit" under their leader, the twenty-year old Lieutenant Ibrahim. Here, the children's experiences of war are revealed to Julia in personalised detail. She learns that they are given drugs to enable them to undertake their gruesome acts, that they are frequently beaten and that the weaker ones are killed by Lieutenant Ibrahim.

The Gola forest sequences allow Julia to be informed about the personal histories of individual child soldiers through which she is able to piece together Citizen's story. They also present a zone of experience outside of realist time and space where the work of healing and reintegration may be done. It is a space where there is a reversal of development back to childhood, allowing the children to be re-educated in a more positive way. Central to this development is the shaman, Bemba $G$, who combines elements of non-modern wisdom of the elders and modern

Cecilia Addei is a Senior Lecturer at the Department of Technical Communication, University of Mines and Technology, Tarkwa, Ghana. She holds a PhD in English from the University of the Western Cape, South Africa.

Email: ceciliaaddei@yahoo.com

(iD) https://orcid.org/0000-0002-1304-9722

DOI: dx.doi.org/10.17159/2309-9070/tvl.v.56i2.5398 
forms of therapy. This combination is what shifts the novel to the mode of magical realism.

Moses, Citizen $\backsim \mathrm{Me}$ has received a fair amount of critical attention that mainly focuses on the novel as one example of a child-soldier narrative that, for the most part, misses the specificities of the question of restoration and redemption highlighted through the Gola forest sequences summarised above. Some of the scholars who have examined the novel argue that Jarrett-Macauley creates Citizen as an innocent victim of war like much other child soldier fiction and human rights discourses. According to Stefanie De Rouck, Jarrett-Macauley presents the child soldiers as being under the control of adults' decisions, thus undermining Citizen's agency and humanity. Sarah Maya Rosen and David M. Rosen also argue that the novel, like much contemporary literature and film, represents child soldiers as abused victims of war. These critics' concerns have been on how the novel creates the child soldier as innocent and without making him responsible for his war-time atrocities.

For some commentators, the novel represents a way of restoring the former child soldier to his state of innocence and vulnerability. Caroline Argyropulo-Palmer analyses the novel as a narrative about the child soldier's journey back to childhood. Ken Junior Lipenga argues that the novel is an exploration of the narrator's attempts to heal the emotional wounds of both Moses and his grandson, Citizen. To him, the novel's aim is precisely to salvage Citizen's humanity, to lead him back across the "bridge to normal childhood" and it does succeed "in redeeming the figure of the child soldier from the stereotype of "monstrosity" (13). I find Joana Spooner's reading of the novel only as national allegory especially problematic. For Spooner, the novel is about the disrupted nation and the child, Citizen, is represented solely as a metaphor of the nation. This allegorical reading fails to consider the powerful ways in which the child soldier, Citizen, is foregrounded as a rounded character and the novel's imperative in seeing the child soldier reconciled to society.

Coming to the question of narrative mode, there are a few articles that highlight the novel's partial magical realist form, as well as its representation of abnormal development. However, none of these analyses explains the full significance of magical realism in terms of its potential in narrative form to reverse the abnormal development of the child soldier. For instance, Allison Mackey describes these child-soldier narratives as "tragic coming-of-age narratives" (100) that encourage the reader to consider what happens to child soldiers after the dehumanising experiences of war. She sees Citizen's refusal to speak, despite Julia's insistence that he does so, as highlighting the need to recognise alternative ways of working through trauma by creatively shaping one's experiences. Mackey's reading constructs war as a "wrong" rite of passage that leaves child soldiers traumatised and calls for alternative ways of healing and restoring them to childhood. However, she does not consider restoration in relation to narrative mode. Like Mackey, Anne Whitehead's study focuses on the novel's representation of restoring former child soldiers to childhood. However, she sees the novel as representing the rehabilitation of child soldiers through indigenous culture. Even though Whitehead argues that the novel is magical realist, she regards magical realism in the novel as representing an "ambitious attempt by Jarrett-Macauley to envision a mode of recovery for the former child soldiers of Sierra Leone that draws inventively on local custom and tradition" (25l-2), alongside other therapeutic modes. Scholarship that does focus on magical realism in Moses, Citizen $\odot$ Me thus fails to identify the ways in which magical realism allows more than just an "African" authenticity. It also embodies the specific narrative capacity to reverse time and allow a re-development and re-education of the "monstrous" child. A factor that has not been considered at all is magical realism's significance in presenting a more ethical technique for conveying traumatic experience that could be sensationalised and turned into voyeuristic spectacle.

Like other child-soldier narratives such as Ahmadou Kourouma's Allah is Not Obliged, Chris Abani's Song for Night and Uzodinma Iweala's Beasts of No Nation, Moses, Citizen $\sim$ Me foregrounds the plight of children enmeshed in wars. These novels represent the atrocities children in war suffer as well as the ones they commit. However, a major point of departure from these child-soldier narratives is that Moses, Citizen $\mho$ Me re-imagines the healing for the child soldier. The novel's major concern is bringing back to normal childhood the child who has matured abnormally. Thus, the novel starts when the war has ended and Citizen, a former child soldier, is rejected because of the crimes he committed during the war, chiefly the murder of his grandmother. Julia, a cousin to Citizen, is concerned with helping him and other former child soldiers to overcome their past trauma and restoring them back to normal childhood. Julia thus becomes an empathetic listener who identifies with the witness, Citizen. This resonates with Stef Craps' argument that "appropriate response to accounts of trauma must involve empathic identification with the witness" (157). This implies that, while the other child-soldier narratives can be said to be anti-Bildungsromane, Moses, Citizen $\mho \mathrm{Me}$ is a converse Bildungsroman. Another major point of departure is that, while most of the child-soldier narratives have child protagonists/narrators, Moses, Citizen $\mho$ Me is narrated in the 
third person and it is arguably more of Julia's story than Citizen's.

Magical realism: debates and departures

Magical realism is a mode of representation that combines realism and fantasy in such a way that neither of the modes is privileged over the other. In an artistic context, the concept of magical realism developed in the early twentieth century in Europe and was catapulted onto the literary scene through the Latin-American 'boom' writers of the mid-to late twentieth century. The debates around magical realism are many. In the context of this article, the idea of the autochthony of magical realism in African modes of representation is considered, as well as the related idea that all writing from the 'third world' must be magical realist. More specifically, however, this article focuses on how Jarrett-Macauley in Moses, Citizen $\sim$ Me sidesteps all of these debates and initiates a departure where magical realism is a therapeutic storytelling mode that allows a reversal of development and re-education, and allows a more ethical form of representation.

As a mode, magical realism challenges the Western tradition of realism, positing instead an alternative universe in which fantastical elements are placed side by side with the real in the process of establishing equivalence between them. The term was coined in 1925 by the German art historian and philosopher, Franz Roh, initially to apply to German post-Expressionist painters of the 1920s. The term later became accepted in the art circles of Italy and South America. Since the 1960s, magical realism has become more generally accepted in Europe and the Americas and has been applied to literature, first by Angel Flores to describe the fiction of Latin American writers like Jorge Luis Borges, Alejo Carpentier, Julio Cortazar, Miguel Ángel Asturias, and Gabriel García Márquez. In recent times, the mode has become no longer a Latin American monopoly and now is very much present in other postcolonial contexts.

Key scholars of the mode include Wendy B. Faris, Maggie Ann Bowers, Amaryll Chanady, Ato Quayson, and Brenda Cooper who have made various attempts to define and analyse how the mode works. According to Faris, magical realism is a combination of realism and the fantastic in such a way that magical elements grow originally out of the reality portrayed (163). For Bowers, since in magical realism the magical is presented as a part of ordinary reality, "the distinction between what is magical and what is real is eroded" (63). According to Cooper, magical realism "strives, with greater or lesser success, to capture the paradox of the unity of opposites; it contests polarities such as history versus magic, the precolonial past versus the post-industrial present and life versus death" (1). Cooper further posits that in magical realism, "the magical is defined as the fictional device of the supernatural, taken from any source that the writer chooses, syncretized with a developed realistic, historical perspective" (16). According to Harry Garuba, "it is the animist world view that presents writers like Ben Okri, García Márquez and Rushdie with the technique and strategy to construct a narrative universe in which transgression and transpositions of boundaries and identities predominate" (271). Garuba further argues that African writers who incorporate spirits, ancestors, and talking animals adopt the strategy to "ascribe a material aspect or existence to what are perhaps only really ideas or states of mind in a manner in which animism imputes spiritual dimensions into material objects" (272). Amaryll Chanady also argues that magical realism is an "amalgamation of a rational and an irrational world view" (21). According to Christopher Warnes, a basic definition of magical realism "sees it as a mode of narration that naturalises or normalises the supernatural; that is to say, a mode in which real and fantastic, natural and supernatural, are coherently represented in a state of equivalence. On the level of the text neither has a greater claim to truth or referentiality" (3).

In Africa, writers who have employed this mode include Ben Okri, Syl Cheney-Coker, B. Kojo Elechi Amadi, Wole Soyinka, Yvonne Vera, Pepetela and Zakes Mda who are said to have been influenced by the Latin American writers. However, this claim has been contested by African magical realist writers. The Nigerian, Molara Wood, author of Indigo, a collection of short stories, asserts in an interview:

Africa is the original "lo real maravilloso". Look at newspaper pages and tell me whether some things reported even in this day and age are not magically real. You have news items that ask you to believe that a thief turned into a goat; goats get arrested as do masquerades; or that some woman gave birth to a horse. I find it interesting that many people recount these with straight faces and listeners often take them as so. (Wood and Ibrahim)

Zakes Mda, the South African novelist, similarly denies that his work is influenced by Latin America since, according to him, he writes in this manner because in his culture "the magical is not disconcerting ... The unreal happens as part of reality" (qtd in Barker 9, original ellipsis). 
These arguments show that even though the mode first became widely known through fiction from Latin America, African magical realism cannot be said to be the product of a Latin American influence but, rather, as a vision and mode of telling born out of Africa's own belief in the reality of the supernatural. This claim is especially justified if one considers the nature of African folktales. In most folktales, supernatural occurrences are recounted in a matter-of-fact manner and listeners take them as real. Garuba has further argued that, in Africa, there is "an animistic mode of thought which is embedded within the process of material, economic activities and then reproduces itself within the sphere of culture and social life" (269). This shows that magical realism is not a borrowed concept in Africa.

Several African stories in which supernatural occurrences are recounted matter-of-factly support the claim that African magical realism is not a Latin American influence but borne out of African belief systems. This resonates with Bowers' argument that in West Africa, magical realism often incorporates local influences to produce a cross cultural literature that emulates the situation of many West Africans today (53). Quayson has also argued that, "African writing takes inspiration from the resources of orality in order to establish a distinctive account of the African world [...] In traditional African oral contexts, the dominant narrative genres that circulate have an element of the magical and the supernatural in them" (159). Magical realism can then be said to be the result of a unique amalgamation of the beliefs and superstitions of different cultural groups. This shows that, while some international writers used the mode to challenge Western realism, Africans use it as an influence of their culture. Also, while some international writers use the mode as metaphorical, for Africans, it is part of their belief system. Kwame Anthony Appiah, for example, suggests: "For Okri, in a curious way, the world of spirits is not metaphorical or imaginary; rather, it is more real than the world of the everyday" (147).

The magical realism used in Moses, Citizen $\mho$ Me could thus be said to have been influenced by West African cultures rather than those of Latin America. This is because it is arguably the African belief in the existence of spirits in material things that influences the writing of most Africans, especially West Africans (Garuba 273). Garuba also argues that magical realism is "too narrow a concept to describe the multiplicity of representational practices that animism authorizes" (272) and thus proposes "animist realism" as the appropriate term. He seems to suggest that the magical elements that exist in most African writing as a result of their animist culture is a broader concept which encompasses magical realism. This is because there seems to be materialisation of spirits in such writings. This means that animist realist writings do not just have magical and supernatural elements like magical realist writings do. However, in Moses Citizen $\approx$ Me, there is nothing like the belief in material objects possessing spirits; rather, the novel alternates between the natural and the supernatural world and supernatural events are recounted in a matter-of-fact manner. I therefore argue that Moses, Citizen $\sim \mathrm{Me}$ is a magical realist novel.

The other side of the coin is that many publishers in the western world have preferred writers in the third world to write in the magical realist mode, especially to present Africa as a place of irrationality. However, the magical realism in Moses, Citizen $\mho \sim M e$ does not endorse the conception of Africa as a place of irrationality, the supernatural, and witchcraft. Rather, the bizarre occurrences that one sees in the civil war are born more out of the pitfalls of the progress and development of the colonially forged nation than a consequence of African primitiveness. Neither is the novel particularly concerned with a literary challenge to the formal realism Ian Watt sees emerging out of eighteenth-century Europe. Instead, magical realism is a form of therapy that enables a reversal of time and the abnormal development of the child soldier that is a product of the violence that has ensued as a consequence of the arbitrary, colonially convenient borders of postcolonial nations. Magic realism also allows a less fraught representation of the child soldier's experience that could so easily be sensationalised, as discussed below.

Moses, Citizen $\sim$ Me has many magical realist features that will be outlined and discussed hereafter. The novel contains real historical events as well as fantastical elements. It alternates between the real world of Julia, the narrator; her uncle Moses; her cousin Citizen; and their neighbour, Anita, and the supernatural world of Gola forest with Bemba $G$ and the child soldiers. The first time the narrative moves to the supernatural world of Gola forest is when Anita makes Julia's hair into big African cornrows that act as pathways into the magical, liminal realm of Gola forest: "Her big plaits were a trap, a device for opening up spaces in my head that hadn't been tampered with since I was a girl. She was using her hairdressing ritual to push African 'bush' rituals into those spaces" (51). Here, hair braiding, which is a typical social activity of African women, introduces African modes of narration into the novel. At first Gola forest appears as if it is in Julia's dream world but her subsequent visits to the place make it part of the reality presented in the novel. From that point the novel alternates between the supernatural world and the physical world without any of the worlds being privileged over the other. This resonates with Ato 
Quayson's postulation that configurations of elements in magical realist texts differ from writer to writer and from text to text. In some, it is a character or characters who possess magical powers, as in Kojo Laing's Woman of the Aeroplanes. In some cases, it is events which are unusual or magical fused with everyday realities as in Pepetela's The Return of the Water Spirit, while in others, the narrative alternates between the magical and the real worlds as in Ben Okri's The Famished Road (175). Like The Famished Road, Moses, Citizen $\sim$ Me alternates between the real world and the supernatural world. There are magical effects merged with everyday reality but these are recounted without any surprise. In the novel, wonders are recounted largely without comment, in a matter-of-fact way, "acceptedpresumably as a child would accept them, without undue questioning or reflection; they thus achieve a kind of defamiliarisation that appears to be natural or artless" (Faris 177). Gola forest and its activities are presented in the novel as part of the reality as there is a thin line between the natural world and the supernatural world in the novel. Julia is able to enter the forest subsequently to see the child soldiers. On her second visit to Gola forest, for instance, she cannot remember anything between leaving Uncle Moses' house and arriving at Gola forest. Magical realism as therapy is explored below.

Reverse development and re-education: magical realism as therapy

Restoring former child soldiers to normalcy is at the core of Moses, Citizen $\sim M e$. Julia's desire to help Citizen to heal from the psychological wounds of his war-time experience and restore him to a state of innocence and vulnerability leads her to visit Doria camp to find out more about Citizen's past. This leads to her imaginative journeys into the world of child soldiers, where she sees the abuse they suffer and the harm they cause, thus gaining insight into how they can be helped.

Moses, Citizen $\mho \mathrm{Me}$ comprises formal realism as well as fantastical elements. It alternates between the real world and the supernatural world as has been stated above. Citizen and Julia live in both the real world and the supernatural world of Gola forest, and it is in the supernatural world of Gola forest that the re-education and reversal of perverted development for child soldiers takes place. This contrary education defies the rules of critical realism because it lacks the logical cause and effect that realism aims to represent. However, this is made possible through magical realism's potential which allows it to represent the rationally and logically impossible. It is a mode of representation that makes the magically imagined become real. As a narrative mode, magical realism has proved to be effective in handling bizarre experiences such as the ones represented in Moses, Citizen $\diamond$ Me because of its special potential. These qualities include its timeless fluidity, its merger of the non-modern and the modern, and its transgression of boundaries in representing human experiences, which makes it overcome ethical problems of representation.

Since development has mostly been represented as a movement from childhood through youth to adulthood as portrayed in the realist Bildungsroman, development from 'adulthood' to childhood would have been very difficult to represent but it is made possible through magical realism. In the Bildungsroman, a young adult leaves his native home, enters a world of the unknown, learns his lesson the hard way, and returns home having developed through his experience. This is realist since the experience can be explained through logical cause and effect. However, reversing the development of an individual who has developed abnormally is not logical and is impossible in realism. Magical realism allows this because its combination of the real and fantastic makes it overcome any limitations in representing human experiences. It is the magical realist Gola forest which makes it possible for children who have formerly engaged in adult violence to allow themselves to be told stories, obey instructions from adult civilians, and play games like children.

As a mode in which time exists in a kind of timeless fluidity, magical realism allows the past to be linked with the present and the future and the supernatural world to link with the real world. Thus, through magical realism, Julia is able to enter the past with the child soldiers to understand their past experience and how they can be helped. The magic realist world of Gola forest makes it possible for Julia to see the conditions under which child soldiers operate. Gola forest is thus a site where one can freely imagine what the child soldier has gone through in order to imagine recuperative methods which are not limited to ordinary realities but transcend what is seen. Julia meets Citizen when the war has ended so, for her to help bring him back to normalcy, there is the need to understand his past experience. She tries to achieve this knowledge by taking an imaginative journey into his past which is made possible through magical realism which is not limited by time and space. Magical realism thus helps Jarrett-Macauley to overcome representational problems of the novel only being realist. 
Also, magical realism brings together the non-modern and modern in the way it syncretises the natural and the supernatural in a matter-of-fact manner. It allows the combination of modern and non-modern ideas in reversing the abnormal development of the former child soldier. Even though Gola forest is a rainforest of spirits, Bemba G combines traditional and modern methods in healing the child soldiers. He tells the children of the need for them to be educated: "He went up to the towering silk-cotton tree and pulled from the centre of it a board on which were scribbled numbers, equations and signs. His fingers approached the board and extracted the square root sign" (89). The teaching of mathematics which is a science is blended with the supernatural since the board on which the exercises are written appears through magic. "Like all forests, the Gola has an intoxicating magical order: scrupulously structured and tinged with babble, unreliable clocks and tracks" (93) yet that is where Julius Caesar, a play, is staged and mathematics is taught. More radically, these magical realist episodes in Gola forest operate to break down the border between "science" and "magic", showing how the one is interfused with the other.

The reversal of psychic malformation in the novel follows the pattern of Victor Turner's 1964 model of the three main stages of traditional initiation: separation, the liminal stage, and the reintegration stage, or the homeaway-home pattern of the realist Bildungsroman. However, unlike traditional initiation and the Bildungsroman where there is development from youth to adulthood, in Moses, Citizen $\mho$ Me, there is a representation of a journey back to childhood. This journey back to childhood takes the form of re-education and redevelopment which is made possible through magical realism. The basic framework is one of traditional initiation where children of age are taken out of their homes into a liminal space where they are educated by elders in the lore of their people after which they are transformed from children to men. Like the rite of passage into adulthood, the inverted 'rite of passage' for actual child soldiers involves three stages. The separation stage is where child soldiers are taken from the war front, from their leaders and their units. The liminal stage is where they are taken to rehabilitation camps which aims to change their war-related violent behaviour and bring them back to a pre-war state of innocence, vulnerability, and need for guidance, while the reintegration stage is where they are sent to surviving members of their families or foster families. The rest of this section focuses on the nature of the 'reverse initiation' experienced by the child soldiers in Gola forest represented in Moses, Citizen $\sim$ Me.

Mathematics seems to be central to the re-education of child soldiers in Moses, Citizen $\mho \sim$ Me. The lesson in mathematics which the former child soldiers receive under Bemba $G$ in Gola forest signifies a re-education into the life of order and prevention of chaos. Mathematics has been defined as a way of applying ideas in a methodical way that encourages one to become systematic. In the same way, Bemba G's lessons in mathematics keep the children busy and calm, and reawaken their interest in a delightfully modest world of sums. By introducing mathematics to the former child soldiers at this stage of their re-education back into childhood, qualities such as critical thinking, creativity, abstract or special thinking, as well as problem-solving abilities are instilled in them at a time they need them most, because these are the qualities that will help them reorganise their lives. But the science of mathematics is infused by magic in Gola forest. Bemba $G$ also tells the children that mathematics is "the place where magic is infinitesimal and mayhem self-induced" (92), but in Gola forest, mathematics is blended with magic to signify the need for the combination of logical reasoning and the belief in the hope embodied in magic in restoring child soldiers to their pre-war state of innocence, a task that ordinarily would seem to defy what is possible.

The storytelling lessons at the Gola forest are meant to help the children work through their trauma, teach them good morals, divert their attention from the tough realities of life, give their lives meaning, and to shape their future. Storytelling has been established in trauma studies as one of the most important strategies of working through trauma. However, most trauma victims are not able to tell their own stories. Craps argues that most trauma victims are not able to communicate their experience for fear that others cannot understand them "but result in distortion and trivialization" (162). This is seen in the way the children are not able to tell their stories when Bemba $G$ asks them to do so. He teaches them the difference between a true story and a made up story and also the storytelling technique of "[b]eginning, middle and end!" (150). Bemba G's insistence on teaching the children to be able to tell their stories signifies the significance of storytelling in working through their trauma and the need for their stories to be told for future generations to learn lessons from them, while the traditional stories Bemba $G$ tells them are meant to teach them moral lessons and also to entertain them. Bemba $G$ highlights the significance and structure of the beginning, middle, and end of narratives to enable the child soldiers to distinguish the end of the war-time story from the beginning of the new story that begins in Gola forest. When Bemba G decides to tell them stories, the eagerness with which they listen to these stories shows their willingness to be children rather 
than engage in adult activities of war and violence: "He told of trees that talked in the night, men who became spiders; he told forest stories that amused the eager listeners" (134). Bemba G's stories teach them moral lessons and help divert their attention from their past lives and the hard truths of their lives as former child soldiers. It also signifies the need to give meaning to their lives and to shape their future.

The re-education of former child soldiers in the liminal zone of Gola forest also involves lessons in dramatic performance. Bemba G helps the children to rehearse and perform Juliohs Siza, the Krio version of Shakespeare's Julius Caesar in Gola forest. Every child soldier is involved in one way or another: acting, singing, drumming, and dancing. This helps the children to understand the ideals that they are being taught. The staging of Juliohs Siza is meant to make the children understand concepts like republican democracy, civic responsibility, and freedom which Shakespeare's Julius Caesar alludes to, as well as the specific motivation behind Thomas Decker's Krio version, Juliohs Siza, when it was written at the time of Sierra Leone's independence. Revisiting Thomas Decker after Sierra Leone's civil war and introducing his ideas is very significant because of what he stood for. Thomas Decker was a Sierra Leonean who held matters of national interest and unity close at heart and contributed significantly to the movement that won independence for Sierra Leone in 1961. Decker's translation of Julius Caesar was "an attempt to deliver an important political message to the new nation on the subject of governance through the example and representation of a once noble servant of the Roman people turned hubristic emperor" (Caulker 209). The performance of Juliohs Siza by former child soldiers is significant since they need to be educated in the message the play conveyed when it was written at the time of Sierra Leone's independence. Besides, storytelling and dramatic performance, both of which are aspects of literature, help the child soldiers to overcome their past experiences. This is in line with Craps' postulation that "literature apparently manages to bridge the divide between the outside and the inside and to penetrate the souls of people who have lived through various historical catastrophes" (162-3).

Bemba G's lessons in dramatic performance also signify the need for the children to imbibe qualities such as self-control, discipline, understanding of interpersonal relationships, and confidence which drama teaches. As the children rehearse in their groups, they learn team work and respect for each other's opinions and how to negotiate power. When Citizen is not prepared to talk, Hinga, a fellow child soldier, says: "We must not press Citizen to say 'yes' if he wants time to think. I apologize. Let us give him time to think" (179). When they realise that Citizen is "afraid of saying the wrong thing at the wrong time, tempting blame and condemnation" (181), they agree that if he has music to offer, that will be more than enough. This shows how the children have internalised democracy through their encounter with Juliohs Siza. On the final day of rehearsal, Hinga and Peter stand behind Citizen to encourage him to break the silence even if it meant only a song: "Peter parted Citizen on the back: 'Can talk now, eh, Citizen, no worries"' (186). This group solidarity among child soldiers presented through magic realism gives a more secure purchase on the possible recuperation of child soldiers than conventional realist techniques would allow. At the final performance of Juliohs Siza in the Gola forest, "[t] he audience was a mixed bunch, a medley of ages, nationalities and types: British and American soldiers in uniform, village people from across the river, some of the Freetown elites with their own kerosene lamps in hand, and more child soldiers walking barefoot" (201). The diversity of the audience signifies the need to involve all parties in the healing of child soldiers and the importance of spreading the news of their ability to be reintegrated. The Krio version of Shakespeare's Julius Caesar, "with intercessions of drumming, dancing and mime" (203) signifies the localisation of foreign ideas. Western forms of healing and reintegrating child soldiers must be administered in accordance with the way of life and beliefs of the people involved. Citizen, playing Brutus' servant, is able to sing, "his flute voice filling our ears" (206). After the show, everybody seems to be surprised at the ability of the child soldiers. A German director who attends the performance asks, "Do you mean child soldiers are capable of this?" (209). This signifies that everything is possible since there is no limit to what happens in the world of magic. At the end, Citizen receives his healing as he dreams about his grandmother who has completely forgiven him and is praying for him. Magical realism signifies that everything is possible, including the forgiveness, total healing, and reintegration of former child soldiers.

Games and sports are also part of the re-education programme at the Gola forest. Bemba G introduces the children to some games which they eagerly play, offering relief from their past trauma. There are also activities in swimming which the children enjoy together as a group. "'Dive him, dive him,' they shouted whenever another boy jumped in and those already in the water swooped upon the newcomer attempting to knock him off-balance" (161). This group sporting activity brings togetherness and engages the children, taking their minds from the battlefield and acting as a symbolic washing away of their guilt. For Citizen, the swimming activity brings out his 
strength: "He was a strong swimmer" (161). It also acts as a turning point for him. Inside the water, he experiences "metamorphosis, he became a ruddy brown butterfly boy, his arms circling the air in rapid motion" (161), thus becoming as fragile as a boy and as graceful as a flying creature.

Unlike the classical Bildungsroman in which the protagonist, after leaving the home, experiences hardships which help him mature into adulthood, the reversal of perverted development through magic realism in Moses, Citizen $\& M e$ allows the former child soldiers to be taken through education in mathematics, narrative and performance, as well as games and sports, activities typical of children, thus helping them to overcome their 'adult' past and restoring their innocence and reliance on adults. Thus, while the experience of the Bildungsroman protagonist outside his home makes him develop into adulthood, the education and games at Gola forest symbolise a journey back to childhood.

The magical Gola forest also allows the former child soldiers to leave the independent adult lives they lived in the army for a childhood life of dependency. At Gola forest, the children no longer fend for themselves but depend on Bemba $G$ for their food, shelter, and protection. Under Bemba G, they eat to their fill after which they throw their dishes up in the air and catch them "in appreciation for good food freely given" (129). This act of throwing dishes also symbolises childish behaviour at the liminal stage of the reversal of perverted education. This total dependency on adults among former child soldiers is not easily achieved in realism as suggested by Kyulanova's study in which the boys undergoing rehabilitation cannot depend on the adults at the rehabilitation centre "because they have become sensitive to the logical gaps and insincerity in their elders' behavior" (31).

Magical realism thus makes it possible to reimagine reversal of psychic malformation which is not possible with the classical Bildungsroman. This is because the classical Bildungsroman's mode of development is only ever forward and the narrator can only ever comment with sadness or disappointment at opportunities lost but can do nothing about the past. Magical realism gives narrative form to the possibility of going back and changing. Thus, the narrative therapy in Moses, Citizen \& Me portrays former child soldiers as potentially functional, people who with a little support, can successfully transform their existences into meaningful civilian lives. This is backed by the real life experience of former child soldiers as discussed below.

Since the end of the war in Sierra Leone, there have been several attempts to heal former child soldiers of their trauma and reintegrate them into society. There were various short-term education and training programmes which operated in the immediate post-war period. These reintegration programmes were organised and implemented by international organisations and the national government to ensure effective re-integration of former child soldiers. Several attempts have also been made to enable former child soldiers to overcome post-traumatic stress disorder. These include Narrative Exposure Therapy, an individual treatment which is based on the principles of cognitive behaviour therapy, exposure therapy, and testimony therapy (McMullen, et al. 1232). Others are group-based therapies like the group trauma-focused cognitive behaviour therapy which is aimed at ensuring that former child soldiers are brought together in the treatment of post-traumatic stress disorder. These group therapies have been said to be more effective than individual therapies because working as a group reduced the risk of stigma and promoted understanding and normalisation of symptoms (McMullen, et al. 1238). In Moses, Citizen e $\mathrm{Me}$, we see the integration of actual therapies used in rehabilitation camps, as well as therapies that derive from Jarrett-Macauley's faith in the power of imaginative stories to heal. As with the group therapies used in actual rehabilitation, Julia in Moses, Citizen $\mho$ Me includes other child soldiers in Citizen's healing and re-education.

The reversal of perverted development in the novel involves three stages: separation from the real world where they suffer rejection, rehabilitation in the supernatural world of Gola forest under Bemba G, and reintegration into the real world. The separation stage is where Citizen is taken from the real world of his grandfather, Moses, where he has become 'unspeakable', unnameable, and under nobody's care, to the supernatural world of Gola forest under Bemba G. The liminal stage of this converse development involves the activities in Gola forest where Citizen, together with other child soldiers, undergoes rehabilitation. Bemba G combines indigenous and modern methods to rehabilitate child soldiers. In the liminal zone of Gola forest, Citizen, together with the other child soldiers, receives education in mathematics, narrative techniques, and stage performance that are all interspersed with magic.

\section{Conclusion}

In this paper, I have shown that Moses, Citizen $\mho \sim M e$, like other child-soldier narratives, foregrounds the plight of children enmeshed in wars, bringing their experiences to the literary public sphere. However, while most of 
such novels represent the lives of their child protagonists/narrators as they go through war, Moses, Citizen $\mho$ Me represents a form of a reversal of perverted development. This reverse development and re-education takes place in the magical Gola forest through a shaman, Bemba G, making the novel alternate between the real world and the supernatural world. This is what tips the narrative into the mode of magical realism, a mode of representation that combines realism and fantasy in such a way that neither of the modes is privileged over the other. I have also argued that magical realism is important in the novel because it allows playing around with time and space by allowing the past to be linked with the present and the future, as well as the non-modern, modern, and the supernatural worlds to link with the real world. Furthermore, magical realism in the novel allows the representation of reversal of perverted development.

\section{Acknowledgement}

I am grateful to CODESRIA and the South African National Institute of Humanities and Social Sciences (NIHSS) for the funding they provided for my $\mathrm{PhD}$ thesis from which this paper originates.

Works Cited

Appiah, Kwame Anthony. "Is the Post-in Postmodernism the Post-in Postcolonial?" Critical Inquiry vol. 17, no. 2, 1991, pp. 33657. DOI: https://doi.org/10.1086/448586.

Barker, Derek Alan. "Escaping the Tyranny of Magic Realism? A Discussion of the Term in Relation to the Novels of Zakes Mda." Postcolonial Text vol. 4, no. 2, 2009, pp. 1-20.

Bowers, Maggie Ann. Magic (al) Realism. Routledge, 2013.

Caulker, Tcho Mbaimba. "Shakespeare's Julius Caesar in Sierra Leone: Thomas Decker's Juliohs Siza, Roman Politics, and the Emergence of a Postcolonial African State." Research in African Literatures vol. 40, no. 2, 2009, pp. 208-27. DOI: https://doi. org/10.2979/ral.2009.40.2.208.

Chanady, Amaryll Beatrice. Magical Realism and the Fantastic: Resolved Versus Unresolved Antinomy. Routledge, 2019.

Cooper, Brenda. Magical Realism in West African Fiction. Routledge, 2012.

Craps, Stef. "Linking Legacies of Loss: Traumatic Histories and Cross-Cultural Empathy in Caryl Phillips's Higher Ground and The Nature of Blood." Studies in the Novel vol. 40, no. 1, 2008, pp. 191-202.

De Rouck, Stefanie. "Moses, Citizen $\mho$ Me by Delia Jarrett-Macauley: A Novel about Child Soldiers, Dealing with Trauma and the Search for Identity.” M. A. Thesis. Ghent U, 2012. https:/lib.ugent.be/catalog/rug01:001891495.

Faris, Wendy B. "Scheherazade's Children: Magical Realism and Postmodern Fiction." Essentials of the Theory of Fiction. Eds. Michael J. Hoffmann \& Patrick D. Murphy. Duke U P, 2005.

Garuba, Harry. "Explorations in Animist Materialism: Notes on reading/writing African literature, culture, and society." Public Culture vol. 15, no. 2, 2003, pp. 261-85. DOI: https://doi.org/10.1215/08992363-15-2-261.

Ibrahim, Abubakar Adam and Molara Wood. "Nigeria: Africa Is the Real Root of Magic Realism." 16 Mar. 2014. https://allafrica. com/stories/201403171689.html. Accessed 4 Jun. 2016

Jarrett-Macauley, Delia. Moses, Citizen \& Me. Granta, 2005.

Kyulanova, Irina. "From Soldiers to Children: Undoing the Rite of Passage in Ishmael Beah's A Long Way Gone and Bernard Ashley's Little Soldier." Studies in the Novel vol. 42, no. 1, 2010, pp. 28-47. DOI: https://doi.org/10.1353/sdn.2010.0012.

Lipenga, Ken Junior. Narrative Enablement: Constructions of Disability in Contemporary African Imaginaries. Diss. Stellenbosch U, 2014.

Mackey, Allison. "Troubling Humanitarian Consumption: Reframing Relationality in African Child-Soldier Narratives." Research in African Literatures vol. 44, no. 4, 2013, pp. 99-122. DOI: https://doi.org/10.2979/reseafrilite.44.4.99.

McMullen, John, et al. "Group Trauma-Focused Cognitive-Behavioural Therapy with Former Child Soldiers and Other WarAffected Boys in the DR Congo: A Randomised Controlled trial." Journal of Child Psychology and Psychiatry vol. 54, no. 11, 2013, pp. 1231-4l. DOI: https://doi.org/10.1111/jcpp.12094.

Quayson, Ato. "Magical Realism and the African novel." The Cambridge Companion to the African Novel. Ed. F. Abiola Irele. Cambridge U P, 2009, pp. 159-76. DOI: https://doi.org/10.1017/ccol9780521855600.010.

Rosen, Sarah M. \& David M. Rosen. "Representing Child Soldiers in Fiction and Film." Peace Review vol. 24, no. 3, 2012 , pp. 305-12. DOI: https://doi.org/10.1080/10402659.2012.704260.

Spooner, Joanna. "Enacting the Nation: Transculturation, Performativity and the Construction of National Identity." Performative Inter-Actions in African Theatre 1: Diaspora Representations and the Interweaving of Cultures. Eds. Kene Igweonu and Osita Okagbue. Cambridge Scholars, 2014, pp. 158-73.

Turner, Victor W. "Betwixt and Between: The Liminal Period in Rites de Passage." Proceedings of the American Ethnological Symposium on New Approaches to the study of Religion, 1964, pp 4-20.

Warnes, Christopher. Magical Realism and the Postcolonial Novel: Between Faith and Irreverence. Palgrave Macmillan, 2009.

Whitehead, Anne. "Representing the Child Soldier: Trauma, Postcolonialism and Ethics in Delia Jarrett Macauley's Moses, Citizen e Me." Ethics and Trauma in Contemporary British Fiction. Eds. Susana Onega and Jean-Michel Ganteau. Brill, 2015, pp. 241-63. DOI: https://doi.org/10.1163/9789401200080 013. 